Int. J. Dev. Biol. 55: 591-596

doi: $10.1387 / \mathrm{ijdb} .103264 \mathrm{me}$

\title{
Chromatin dynamics of the developmentally regulated $P$. lividus neural alpha tubulin gene
}

\author{
MARCO EMANUELE, SALVATORE COSTA, MARIA ANTONIETTA RAGUSA and FABRIZIO GIANGUZZA* \\ Dipartimento di Scienze e Tecnologie Molecolari e Biomolecolari, Università di Palermo, Italy
}

\begin{abstract}
Over 40 years ago, Allfrey and colleagues (1964) suggested that two histone modifications, namely acetylation and methylation, might regulate RNA synthesis. Nowadays it is universally accepted that activation of gene expression strictly depends on enzymatic mechanisms able to dynamically modify chromatin structure. Here, using techniques including DNasel hypersensitive site analysis, chomatin immunoprecipitation and quantitative PCR analysis, we have analyzed the dynamics of histone post-translation modifications involved in developmentally/spatially controlled activation of the sea urchin PITalpha2 tubulin gene. We have demonstrated that only when the PITalpha2 core promoter chromatin is acetylated on H3K9, tri-methylated on H3K4 and not di-methylated on H3K27, RNA pol II can be enrolled. In contrast, we have shown that when chromatin is methylated both on H3K9 (me2/3) and H3K27 (me2) and mono methylated on H3K4 the promoter is not accessible to RNA pol II. Our results suggest that, during $P$. lividus embryogenesis, both HAT/HDAC and HMT/HDM activities, which are able to regulate accessibility of the PITalpha2 basal promoter to RNA polymerase II, are coordinately switched-on.
\end{abstract}

KEY WORDS: Paracentrotus lividus, chromatin modification, epigenetic reprogramming, nervous system

\section{Introduction}

Once considered a mere DNA packaging device, chromatin is now viewed as a highly dynamic structure that affects all DNA transactions within the nucleus, namely transcription, replication, repair, recombination and transposition, as well as chromosome segregation. The basic unit of chromatin is the nucleosome, which is composed of $147 \mathrm{bp}$ of DNA wrapped around a protein core of two molecules of each of $\mathrm{H} 2 \mathrm{~A}, \mathrm{H} 2 \mathrm{~B}, \mathrm{H} 3$ and $\mathrm{H} 4$ histones. Covalent modifications of the nucleosome core, incorporation of histone variants, DNA methylation and other factors such as chromatin remodeling enzymes or small RNAs are thought to define distinct chromatin states and modulate the accessibility of DNA, either directly or indirectly through the recruitment of additional effectors (Rando and Ahmad, 2007; Campos and Reinberg, 2009; Li et al., 2007).

Over the past decade, studies have shown that histones can undergo to a vast range of post translational modifications (PTMs), either before or after their incorporation into nucleosomes. PTMs, that are particularly numerous on the unstructured $\mathrm{N}$-tails of histones $\mathrm{H} 3$ and $\mathrm{H} 4$, include acetylation, methylation, ubiquitination or sumoylation of lysine residues, methylation of arginine residues and phosphorylation of serine and threonine residues. Moreover, up to two and three methyl groups can be respectively added to arginine and lysine residues, further enriching the repertoire of histone PTMs. Finally, specific combinations of chromatin modifications constitute the epigenetic marks of eukaryotic genome and identify different chromatin functional states, that can also be inherited (Kouzarides, 2007; Rando and Ahmad, 2007; Feil, 2008; Mellor et al., 2008; Vaquero, 2009)

Eukaryotes have evolved regulatory mechanisms to induce structural changes to chromatin in response to environmental and cellular cues, accomplished by specific enzymatic activities (mainly HAT/HDAC and HMT/HDM) and able to modulate chromatin packaging and regulator binding, thus affecting the recruitment of specific proteins to DNA. One of the emerging challenges in the study of chromatin covalent modifications is to understand the role played by these marks in different chromatin functional contexts as well as to characterize the factors regulating and targeting these enzymatic activities to chromatin.

Abbreviations used in this paper: ChIP, chromatin immunoprecipitation; HAT, histone acetyl transferase; HDAC, histone deacetlylase; HDM, histone demethylase; HMT, histone methyltransferase; PTMs, post-translational modifications.

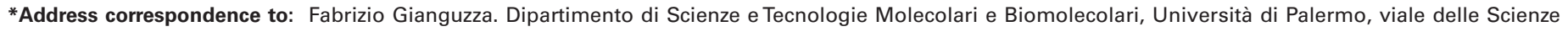
Ed.16, 90128 Palermo, Italy. Fax: +39-091-657-7430. Tel: +39-091-238-97412. e-mail: gianfab@unipa.it
} 
Thus, in general, histone acetylation is thought to be associated with active transcription, regardless of the site of acetylation. In contrast, histone methylation has proven to be a far more complex entity: not only do distinct histone lysine residues have different, sometimes opposing, functions when methylated, but different degrees of methylation (mono-, di-, or tri-methylation) on the same residue may have vastly differing functions (Campos and Reinberg, 2009; Robertson et al., 2008; Mosammaparast and Shi, 2010).

All echinoderm larvae have a nervous system that appears to be centered on the ciliary band with what may be sensory ganglia (apical, oral and lateral ganglia), and that control swimming and feeding. In particular the animal plate of the sea urchin embryo becomes the apical organ, a sensory structure of the larva, while the neurogenic ciliated band becomes morphologically distinct after gastrulation between the oral and aboral ectoderm territories with lineage contributions from both (Nakajima et al., 2004; Yaguchi et al., 2006).

We previously identified and characterized a specific alpha tubulin mRNA (alpha2) of the sea urchin Paracentrotus lividus. Its expression starts from the hatching blastula stage in the apical plate and progressively increases during embryogenesis (Gianguzza et al., 1989), maintaining its localization restricted to the larval nervous system (apical, oral and lateral ganglia and ciliary band; Gianguzza et al., 1995). Accordingly, the deduced encoded protein is a specific terminal product of neural differentiation: it is indeed an axonal glutamylated tubulin isotype, homologous to the corresponding neural mammalian isotype (Casano et al., 1996; Tuszynski et al., 2006). We also isolated the corresponding PITalpha2 gene, consisting of three exons and two introns and the regulatory sequences involved both in its basal and in its spatiotemporal transcription regulation. These regulatory sequences are in fact able to drive a proper spatio-temporal expression profile of a reporter gene when microinjected into the embryos. Finally, gene transfer experiments show that sequences required for proper expression are localized in a region from -4.5 to $+0.8 \mathrm{~Kb}(5$, upstream and first intron sequences; Costa et al., 2004; Ragusa et al., in press) and that the minimal promoter sequence is between -50 and +150 bp (Gianguzza et al., unpublished data).

In this study we used chromatin immunoprecipitation (ChIP) to demonstrate that this core promoter region of the PITalpha2 gene (now re-named PITuba1a - Ragusa et al., in press) gains transcriptional competence depending on specific and developmentally controlled histone tails modifications.

\section{Results}

\section{Core promoter accessibility}

Since transcription of the PITalpha2 gene is developmentally regulated (Gianguzza et al., 1989), we supposed that its core promoter could be differentially accessible to RNA polymerase during sea urchin development. In order to investigate this aspect, nuclei from $P$. lividus embryos at both morula (when the gene is off) and gastrula stage (when the gene is switched-on) were treated with increasing amounts of DNasel and analyzed by Southern blot hybridization.

To identify DNasel hypersensitive sites both upstream and downstream of TSS (Transcription Start Site), we digested DNA with Sall restriction enzyme that releases a genomic fragment of $2.5 \mathrm{~Kb}$, including a reverse CAAT box, a canonic TATA box the TSS and the first and second intron, and hybridized it to a radioactive $100 \mathrm{bp}$ probe complementary to the 5 ' end of the $2.5 \mathrm{~Kb}$ Sall fragment. Numerous hypersensitive DNAsel sites were observed only at the gastrula stage (see scheme at Fig. 1) at level of core promoter, first intron and second intron. This observation suggested that a different chromatin structure, permissive for transcription, was acquired, during the development, by the PITalpha2 gene and particularly by its core promoter at gastrula stage, in agreement with its developmentally regulated transcriptional activation at this stage (Gianguzza et al., 1989).

\section{Post translational modifications (PTMs) and PITalpha2 gene activation}

Using ChIP and conventional PCR, we preliminarly investigated whether transcriptional regulation was linked to a modification of H3 histone acetylation and methylation pattern both in core promoter and in the first intron of PITalpha2 gene. The results (not shown) demonstrated a tight correspondence between PITalpha2 gene transcriptional activity at gastrula stage and the general lysine acetylation of $\mathrm{H} 3$ tails in both analyzed regions, while very low association of H3K9me2 to the analyzed regions was found. Conversely, transcriptional silencing at morula stage correlates, as expected, with a reciprocal pattern of histone modifications, i.e. $\mathrm{H} 3 \mathrm{~K} 9$ dimethylation, and a remarkably reduced $\mathrm{H} 3$ acetylation.

The core promoter lies at the center of the transcription process, therefore it is often an overlooked component in the regulation of gene expression. Moreover both core promoter accessibility and
$1000 \mathrm{bp}$

TATA $\diamond A U G \nabla$ Sal $\nabla$

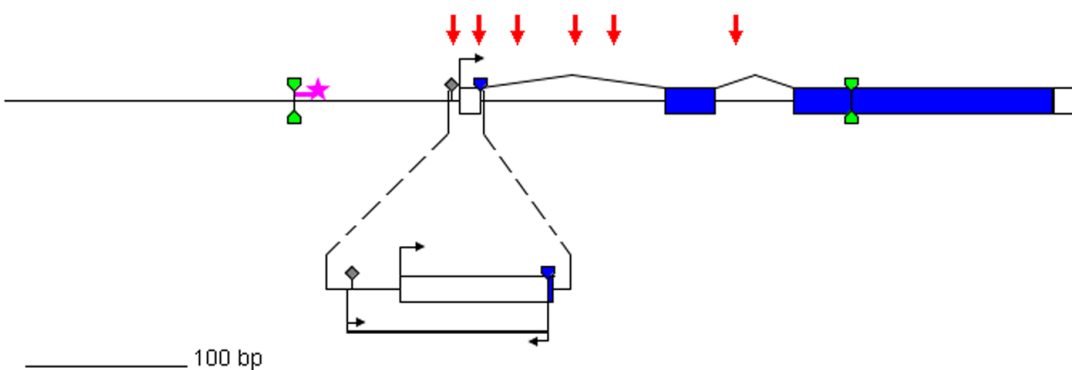

Fig. 1. Map of the PItalpha2 gene and schematic representation of the DNase I-hypersensitive sites observed at gastrula stage. The gene structure was already described by Costa et al., (2004). Solid boxes represent exon regions (blue: coding regions; white: 5' and 3' UTRs). Downward arrows indicate the centers of DNasel cutting sites at the gastrula stage. Upward-downward (double green) arrows show positions of Sall restriction sites. The position of the probe sequence (thick pink line with star) is also shown. Positions of TATA box and TSS (grey diamond and black arrow, respectively) are indicated. An enlarged view of the 5 '-flanking region of the PITalpha2 gene is drawn under the main map. The position of the GPCR fragment used for the ChIP analysis of the promoter is shown underneath (between arrows). The upper bar corresponds to $1000 \mathrm{bp}$ of the main map, while the lower bar corresponds to $100 \mathrm{bp}$ of the enlarged view. 

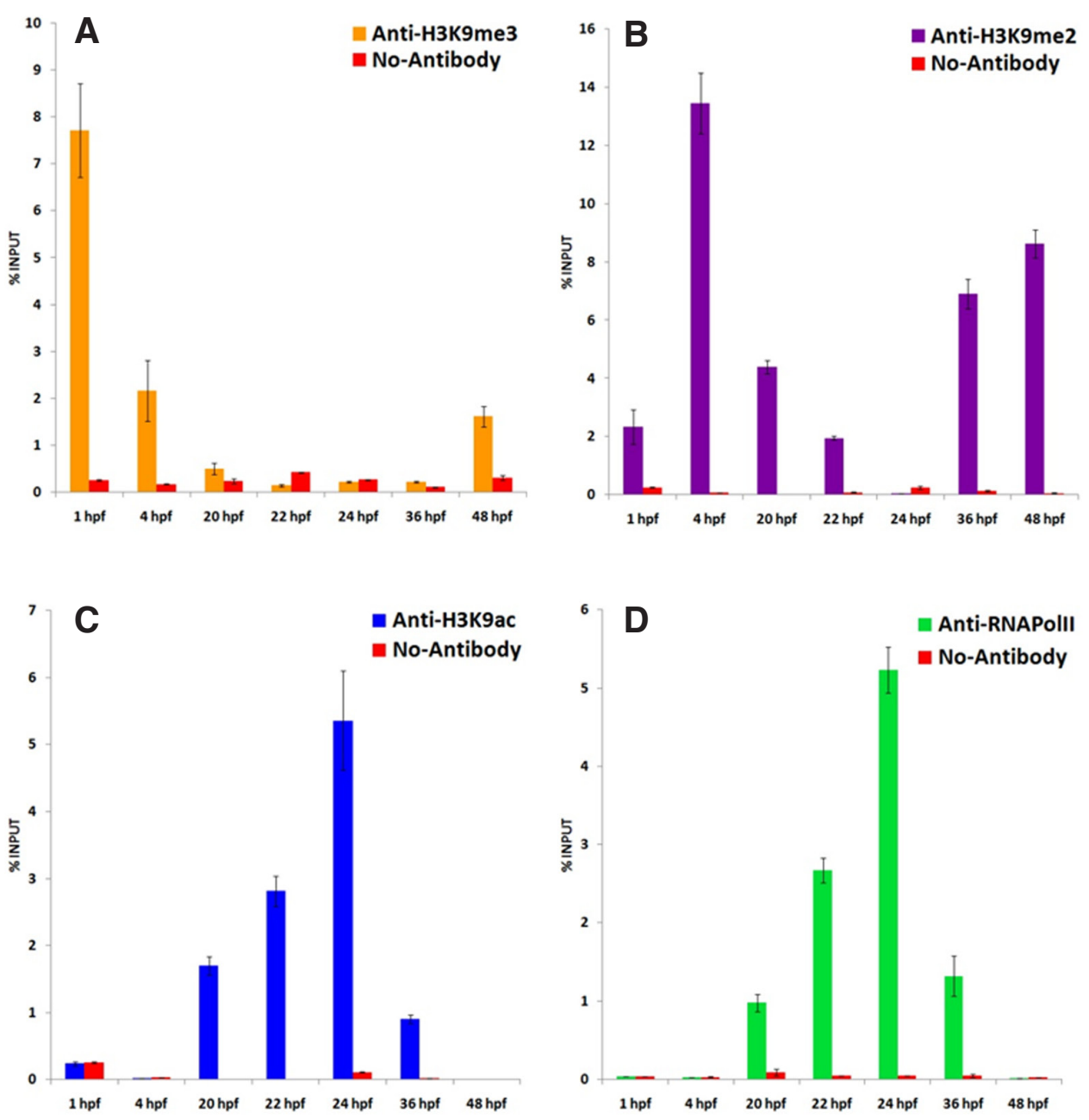

Fig. 2. Quantitative chromatin immunoprecipitation (qChIP) analysis of the PITalpha2 gene core promoter. Input chromatin was isolated from sea urchin embryos at different developmental stages (from 1 to 48 hour post fertilization, hpf). Chromatin was immunoprecipitated using antibodies against H3K9me3 (A), H3K9me2 (B), H3K9ac (C), RNA pol I/ (D), and analyzed by real-time PCR. Bars represent the mean $( \pm S D)$ of three independent experiments. Red bars: control; colored bars: abundance of modified histones or RNA pol II. Data were normalized with respect to the standard curve and to $1 \%$ input values. Real-time PCR primers were designed to amplify a 120bp region containing the TATA box and the TSS. qChIP experiments were carried out as described in Material and Methods.

core-promoter recognition complexes (both prototypic and nonprototypic) may play a critical regulatory role in driving cell specific programs of transcription during development and in maintaining active gene expression across cell divisions (Goodrich and Tjian, 2010; Juven-Gershon and Kadonaga, 2010).

Then to better understand the relationship between chromatin modifications and PITalpha2 transcriptional activation during sea urchin development we decided to carry out time course ChIP-qPCR assays just on PITalpha2 core promoter sequences, using a set of antibodies directed against different PTMs of H3 tails (see M\&M).

The results of these experiments clearly showed that the H3K9 of the nucleosomes present on the core promoter are strongly 3-methylated at early developmental stages (1 - 4 hrs) (Fig. 2A) they are then de-methylated (Fig. 2B) and increasingly acetylated (Fig. 2C) with a peak of acetylation at $24 \mathrm{hrs}$ of development. This dynamics of the PTMs is in agreement with the expression profile of the PITalpha2 tubulin gene during development, in fact the alpha2 transcript appears only from blastula stage (about 15 hrs of development), accumulating during late developmental stages (Gianguzza et al., 1989).

To strongly correlate these PTMs with the developmental regulation of transcription, we performed time course ChIP-qPCR experiments also with anti-RNA pol II antibodies.

The results (Fig. 2D) showed that RNApol II is engaged on the PITalpha2 core promoter between 20 and 36 hrs of development, in concomitance with the acquirement of the acetylated state by H3K9.

Interestingly we also found evidence that around $36 \mathrm{hrs}$ of development a new H3K9 methylation wave occurs. H3K9 is indeed clearly deacetylated and progressively re-methylated, regaining a tri-methylated state at 48 hrs (Fig. $2 \mathrm{~A}-\mathrm{C}$ ). These results are in agreement with previous evidence suggesting that tubulin genes are transcriptionally regulated up to the gastrula stage and post-transcriptionally regulated thereafter. The accumulation of tubulin mRNA after gastrulation has been indeed attributed to an ontogenetic increase in tubulin RNA stability, assayed by actinomycin D chase and RNA gel blot hybridization (Gong and Brandhorst, $1988 \mathrm{a}, \mathrm{b}$ ).

A leading role in terms of histone code and transcriptional regulation is also played by methylation of $\mathrm{H} 3 \mathrm{~K} 4$ (Robertson et al., 2008; Rudolph et al., 2007). For H3K4 methylation a dual role has been highlighted: when H3K4 is mono-methylated chromatin structure has been found to be more packed, whereas tri-methylated $\mathrm{H} 3 \mathrm{~K} 4$ associates with a chromatin open structure, accessible to transcriptional regulatory proteins. Our results (Fig. 3A-B) performed with anti-H3K4 me1 or anti-H3K4me3 antibodies are in agreement both with bibliographic data and with the previous results of this paper. H3K4 methylation levels in the nucleosomes present in PITalpha2 core promoter change indeed during development. In particular, during the first hours (up to $4 \mathrm{hrs}$ ) of development, when the PITalpha2 gene is not expressed, we found that $\mathrm{H} 3 \mathrm{~K} 4$ is mainly mono-methylated. Later in development (from 20 to $36 \mathrm{hrs}$ ) it progressively becomes tri-methylated, with a peak at $24 \mathrm{hrs}$, regaining then a mono-methylated state. From a comparative analysis, a full correspondence of $\mathrm{H} 3 \mathrm{~K} 4$ methylation and H3K9 methylation/acetylation dynamics emerged, thus confirming a tight association of these PTMs with the acquirement of a transcriptionally active conformation by the PITalpha2 tubulin gene. Furthermore, there is a tight correspondence between the 

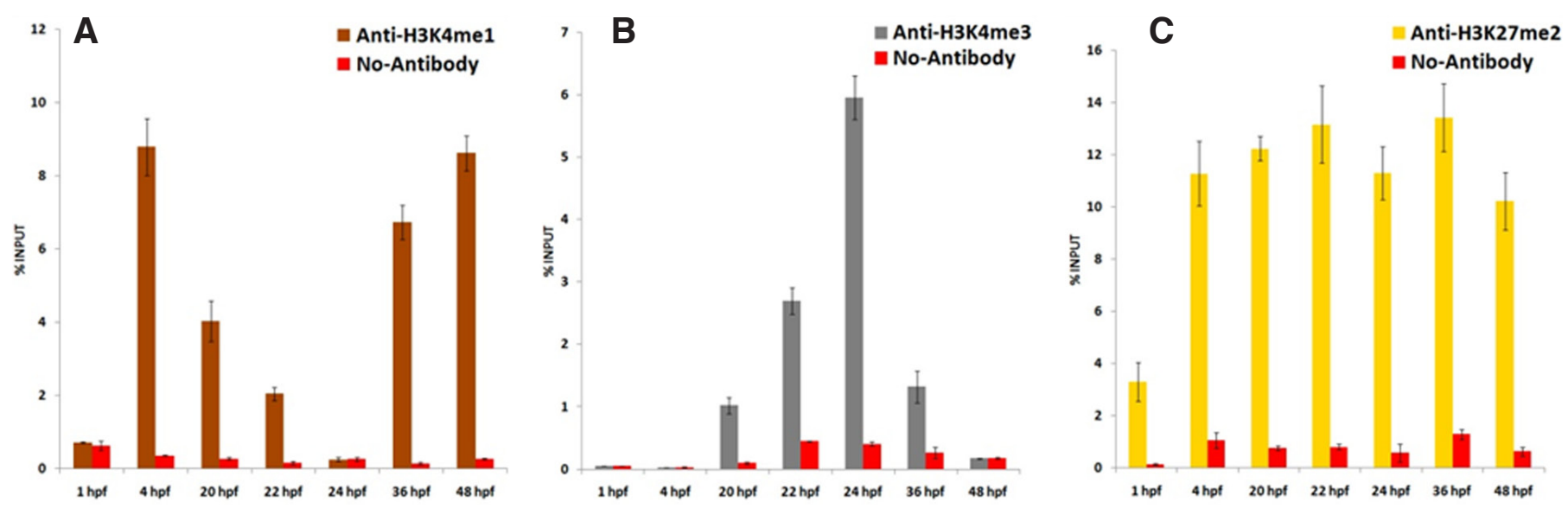

Fig. 3. Quantitative chromatin immunoprecipitation (qChIP) analysis of the PITalpha2 gene core promoter. Chromatin from different sea urchin embryo developmental stages was immunoprecipitated with antibodies against H3K4me1 (A), H3K4me3 (B) or H3K27me2 (C) and analyzed by realtime PCR (for details see Fig. 2).

accumulation of $\mathrm{K} 4 \mathrm{H} 3 \mathrm{me} 3$ and the maximum association of RNA pol II with the core promoter (Fig. 2D). It is interesting to note that the methylation of H3K4 has been related with the transcriptional activation of genes and is a strong predictor for RNA pol II promoters. In particular, the trimethylated form of H3K4 has been found primarily around the transcription start sites of active genes (van Ingen et al., 2008) as in our case.

A

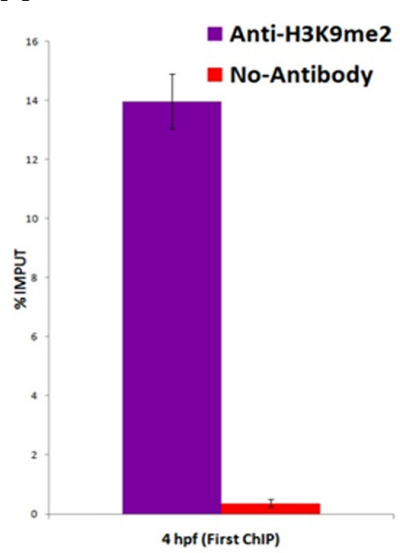

B

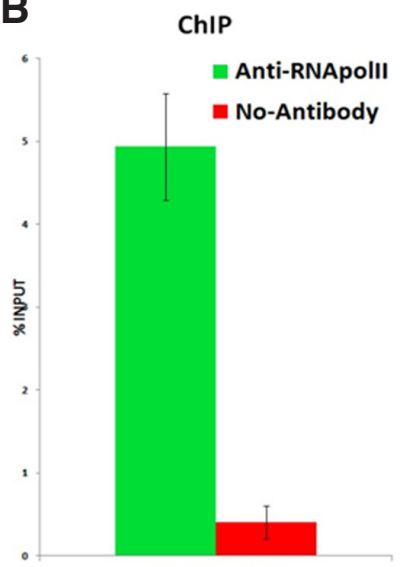

24 hpf (First ChIP)

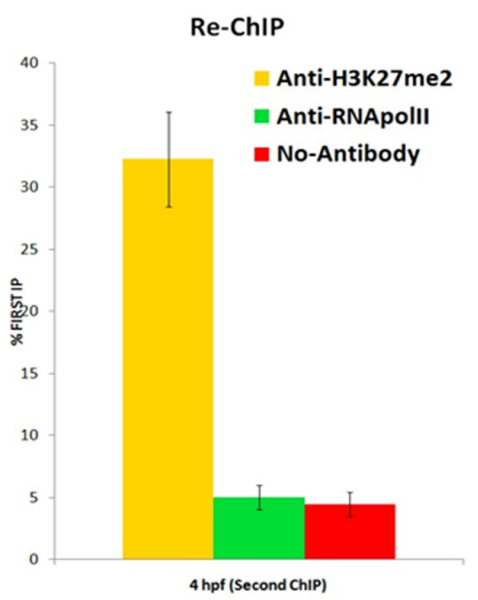

Re-ChIP

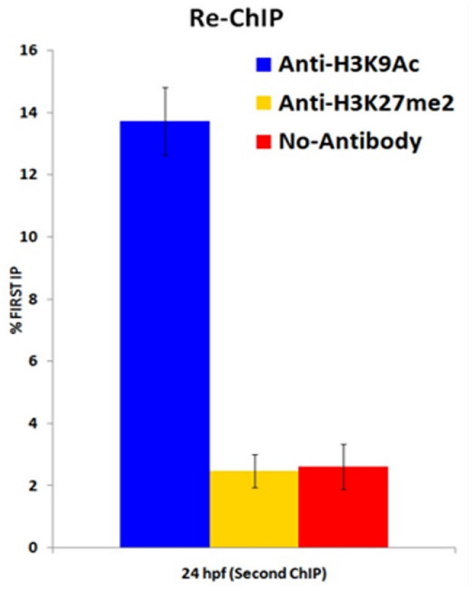

Finally, we also analyzed the methylation state of H3K27 by using anti-H3K27me2 antibody. Surprisingly, the results of the time course ChIP-qPCR experiments (Fig. 3C) showed that H3K27 of the nucleosomes present on the core promoter were uniformly methylated at all developmental stages. Since H3K27me2 is not a clear mark of constitutive heterochromatin, we checked whether H3K27me2 histone tail modification was associated with activation or repression of PITalpha2 gene by sequential chromatin immunoprecipitation (Re-ChIP). This technique has been used to address, in a qualitative manner, whether two proteins can simultaneously co-occupy a stretch of DNA (Furlan-Magaril et al., 2009; Medeiros et al., 2009). We applied the Re-ChIP protocol to analyze chromatin modifications on core promoter of PITalpha2 gene at two developmental stages: the morula stage, when the gene is not expressed, and the gastrula stage, when the gene is transcriptionally active only in the neural territory (Gianguzza et al., 1995). For the first ChIP performed on chromatin extracted from the morula stage we used the anti-H3K9me2 antibody, and for the Re-ChIP, we used an anti-H3K27me2 antibody or an anti-RNA pol II antibody. For the first ChIP on chromatin extracted from the gastrula stage we used the anti-RNA pol II antibody and for the Re-ChIP anti-H3K27me2 or anti-H3K9Ac antibodies.

Thus we demonstrated the co-presence of H3K9me2 and H3K$27 m e 2$ on chromatin of morula stage, when the PITalpha2 gene is not transcribed in any cells (Fig. 4A).

On the contrary, performing at gastrula stage the first ChIP with the anti-RNA pol II antibody that permit to sort only transcribed chromatin, we observe the presence of H3K9Ac but not of H3K-

Fig. 4. Re-ChIP analysis of the PITalpha2 gene core promoter. The bars show the qPCR results of the ChIP and Re-ChIP pull-downs experiments. (A) Input chromatin was isolated from sea urchin embryos at morula stage (4 hpf). The first ChIP was performed with Anti-H3K9me2 (left); the second ChIP was performed on first IP with H3K27me2 or RNA pol II antibodies (right). (B) Input chromatin isolated from gastrula stage (24 hpf). The first ChIP was performed with Anti-RNApolll (left); the second ChIP was performed on first IP with H3K9ac or H3K27me2 antibodies (right). The ChIP results obtained by 3 independent replicate experiments are represented as percentage $( \pm S D$ ) of input chromatin (first ChIP) or as percentage $( \pm S D$ ) of the first IP (second ChIP). 
27me2 in PITalpha2 core promoter (Fig. 4B).

\section{Discussion}

Histone modifications are believed to mark local chromatin for activation or silencing of gene activity. In general terms, hypoacetylation, H4K20me3, H3K9me3 and H3K27me2/3 are typical marks of silenced chromatin, whereas hyperacetylation, H3K4me3 and H3K36me3 are hallmarks of actively transcribed chromatin.

It is, however, becoming increasingly clear that a single histone mark does not proscribe a final outcome with respect to transcription or the local chromatin structure. For example, marks such as $\mathrm{H} 3 \mathrm{~K} 9 \mathrm{me} 2 / 3$ and $\mathrm{H} 3 \mathrm{~K} 4 \mathrm{me} 2 / 3$, although enriched on either silenced or actively transcribed genes, respectively, are also present in the reciprocal states (Cloos et al., 2008; Mosammaparast and Shi, 2010). Therefore the association between a specific epigenome and its transcriptional status is more complicated (Feil, 2008; Meagher, 2010).

On the other hand, in the sea urchin embryo, the correlation between modification of nucleosomes and transcriptional competence has been poorly investigated and the few reports that in this embryonic system have dealt with chromatin architecture and transcription, concern the histone genes (Di Caro et al., 2007).

All these reasons led us to investigate the existence of developmentally dependent changes of the PITalpha2 gene epitype by ChIP.

We found that specific histone modifications (H3K9Ac, H3K$4 \mathrm{me} 3$ ), which induce an accessible chromatin conformation, occur dynamically at level of core promoter in the same developmental window previously highlighted as the temporal interval in which the PITalpha2 neural gene is expressed (Gianguzza et al., 1989; Gianguzza et al., 1995).

We found also a constitutive presence of dimethylated H3K27, that is classically implicated in silent chromatin. Recently, bivalent domains that possess both activating and repressive modifications (H3K27me and H3K4me) have been found. The enrichment of these opposing modifications with further PTMs (i.e. H3K9 acetylation/methylation) can dictate distinct functional types of chromatin (Bernstein et al., 2006; Mosammaparast and Shi, 2010; Cloos et al., 2008, Kouzarides, 2007).

We demonstrated that only when the core promoter chromatin is acetylated on $\mathrm{H} 3 \mathrm{~K} 9$, tri-methylated on $\mathrm{H} 3 \mathrm{~K} 4$ and not di-methylated on H3K27, RNA pol II can be enrolled, certainly in a specific temporal window and probably only in the neural territory. On the other hand, we showed that when the core promoter chromatin is methylated both on H3K9 (me2/3) and H3K27 (me2) and mono methylated on H3K4 the chromatin is not accessible to RNA pol II. Thus specific and related PTMs certainly limit the developmental temporal window of gene activation and probably contribute in localizing transcription to neural territory, repressing transcription in non neural territories.

In conclusion, our results demonstrate, for the first time in sea urchin, a tight association between the dynamics of specific histone modifications and the defined gene functional outcomes, demonstrating also a high degree of conservation of epigenetic regulation between echinodermata and higher organism during development. Moreover these data could represent the first demonstration that HAT/HDAC and HMT/HDM enzymatic activity are coordinately switched-on during sea urchin development to regulate the expression of a specific gene.

\section{Materials and Methods}

\section{Embryo culture}

Gametes were collected from gonads of the sea urchin $P$. lividus from the west coast of Sicily. Eggs were fertilized at a concentration of $5000 / \mathrm{ml}$ and the embryos were grown under gentle rotation at $18^{\circ} \mathrm{C}$ in Milliporefiltered seawater (MFSW) containing antibiotics (50 mg/l streptomycin sulfate and $30 \mathrm{mg} / \mathrm{l}$ penicillin). Developmental stages were monitored by optical microscopy.

\section{DNasel hypersensitive site analysis}

Embryos, at the morula (4 hours post fertilization, hpf) and gastrula (24 hpf) stages, were immobilized by adding SDS 20\% (0,3 $\mathrm{ml} / \mathrm{l}$ seawater) and allowed to settle. Functionally intact nuclei were isolated according to von Holt et. al. (1989), and stored in liquid nitrogen. After thawing, nuclei were digested with DNasel according to Sippel et al., (1996). Typically, 0, 3, 6, 12 and 24 units of enzyme were added for $2 \times 10^{7}$ nuclei and the nuclei were incubated for $15 \mathrm{~min}$ at $4^{\circ} \mathrm{C}$. For DNasel hypersensitive site mapping, the isolated genomic DNA from DNasel-treated nuclei was digested with Sall restriction enzyme and analyzed by conventional Southern hybridization procedure.

\section{ChIP and qPCR analysis}

Embryos (500 $\mu$ l aliquots) were recovered at the desired stage of development $(1,4,20,22,24,36$ and $48 \mathrm{hpf})$, and incubated with $1 \%$ formaldehyde for $10 \mathrm{~min}$. Crosslinking was stopped by addiction of glycine to a final concentration of $0.125 \mathrm{M}$, and cross-linked chromatin was sonicated to reduce DNA size to 200-500 base pairs. Sonicated chromatin was then used for the ChIP analysis. All ChIP reactions were made with ChIP-IT TM Express Chromatin Immunoprecipitation Kit (Active Motif \#53008), according to the manufacturer's protocols. Immunoprecipitation was carried out with mouse antibodies (previously tested against sea urchin proteins) against RNA pol II (Abcam \#ab24759), H3K9ac (Abcam \#ab4441), H3K9me2 (Abcam \#ab1220), H3K9me3 (Abcam \#8898), H3K4me3 (Abcam \#ab1012), H3K4me1 (Abcam \#ab8895) and H3K27me2 (Abcam \#ab24684).

Quantitative real time PCR was performed using the SsoFast EvaGreen Supermix kit (BioRad \#172-5201), in a $20 \mu \mathrm{l}$ QPCR reaction volume, according to the manufacturer's protocols. Primers used were: Real-Prom-1D (5'- GGGGTATAAATACGAGTGCGCCG) and Real-Prom-1R (5'- GATGATACATTATTCGAATTCGAAG) that amplify a fragment including the TATA box and the TSS (from -33 to + 92). The samples were amplified using an BioRad CFX96 Real-Time PCR System, and quantified with a calibration curve obtained with DNA isolated from crosslinked, sonicated chromatin. Data normalization was made as \% of Input method.

For the Re-ChIP, precipitated complexes from the first ChIP were eluted by a 10 min incubation with $100 \mu$ l of ChIP elution buffer $(50 \mathrm{mM}$ Tris- $\mathrm{HCl}$, $\mathrm{pH} 7.5,10 \mathrm{mM}$ EDTA and $1 \%$ SDS) at $68^{\circ} \mathrm{C}$ and a second ChIP reaction was carried out with ChIP-IT ${ }^{\mathrm{TM}}$ Express Chromatin Immunoprecipitation Kit.

\section{Acknowledgements}

We would like to thank G. Spinelli and I. Di Liegro for their critical reading and feedbacks on this manuscript. We would also like to apologize with all our colleagues whose work was not properly cited due to space restriction. This work was supported by MIUR (ex 60\%) grant to F.G.

\section{References}

ALLFREY VG, FAULKNER R, MIRSKY AE. (1964) Acetylation and methylation of histones and their possible role in the regulation of RNA synthesis. Proc. Natl. Acad. Sci. USA 51: 786-794.

BERNSTEIN BE, MIKKELSEN TS, XIE X, KAMAL M, HUEBERT DJ, CUFF J, FRY B, MEISSNER A, WERNIG M, PLATH K, JAENISCH R, WAGSCHAL A, FEIL R, SCHREIBER SL, LANDER ES. (2006) A bivalent chromatin structure marks key developmental genes in embryonic stem cells. Cell 125: 315-326.

CAMPOS EI, REINBERG D. (2009) Histones: annotating chromatin. Annu Rev 
Genet 43: 559-599.

CASANO C, RAGUSA M, CUTRERA M, COSTA S, GIANGUZZA F. (1996) Spatial expression of alpha and beta tubulin genes in the late embryogenesis of the sea urchin Paracentrotus lividus. Int J Dev Biol 40: 1033-1041.

CLOOS PA, CHRISTENSEN J, AGGER K, HELIN K. (2008) Erasing the methyl mark: histone demethylases at the center of cellular differentiation and disease. Genes Dev 22: 1115-1140.

COSTAS, RAGUSAMA, DRAGO G, CASANO C, ALAIMO G, GUIDAN, GIANGUZZA F. (2004) Sea urchin neural alpha2 tubulin gene: isolation and promoter analysis. Biochem Biophys Res Commun 316: 446-453.

DI CARO V, CAVALIERI V, MELFI R, SPINELLI G. (2007) Constitutive promoter occupancy by the MBF-1 activator and chromatin modification of the developmental regulated sea urchin alpha-H2A histone gene. J Mol Bio/365: 1285-1297.

FEIL R. (2008) Epigenetics, an emerging discipline with broad implications. C R Biol 331(11): 837-843.

FURLAN-MAGARILM, RINCÓN-ARANO H, RECILLAS-TARGAF. (2009) Sequentia chromatin immunoprecipitation protocol: ChIP-reChIP. Methods Mol Biol 543: 253-266.

GIANGUZZA F, DI BERNARDO MG, SOLLAZZO M, PALLA F, CIACCIO M, CARRA E, SPINELLI G. (1989) DNA sequence and pattern of expression of the sea urchin (Paracentrotus lividus) alpha-tubulin genes. Mol Reprod Dev 1: 170-181.

GIANGUZZAF, CASANO C, RAGUSAM. (1995) Alpha-tubulin marker gene of neural territory of sea urchin embryos detected by whole-mount in situ hybridization. Int $J$ Dev Biol 39: 477-483.

GONG ZY, BRANDHORST B. (1988)a Autogenous regulation of tubulin synthesis via RNA stability during sea urchin embryogenesis. Development 102: 31-43.

GONG ZY, BRANDHORST BP. (1988)b Multiple levels of regulation of tubulin gene expression during sea urchin embryogenesis. Dev Biol 130: 144-153.

GOODRICHJA, TJIANR. (2010) Unexpected roles for core promoter recognition factors in cell-type-specific transcription and gene regulation. Nat Rev Genet 11:549-558.

JUVEN-GERSHON T, KADONAGA JT. (2010) Regulation of gene expression via the core promoter and the basal transcriptional machinery. Dev Biol 339: 225-229.

KOUZARIDEST. (2007) Chromatin modifications and their function. Cell128: 693-705.

LI B, CAREY M, WORKMAN JL. (2007) The role of chromatin during transcription. Cell 128: 707-719.

MEAGHER RB. (2010) The evolution of epitype. Plant Cell 22: 1658-1666.

MEDEIROS RB, PAPENFUSS KJ, HOIUM B, COLEY K, JADRICH J, GOH S, ELAYAPERUMAL A, HERRERA JE, RESNIK E, NI H. (2009) Novel sequential ChIP and simplified basic ChIP protocols for promoter co-occupancy and target gene identification in human embryonic stem cells. BMC Biotechnol 9: 59.
MELLOR J, DUDEK P, CLYNES D. (2008) A glimpse into the epigenetic landscape of gene regulation. Curr Opin Genet Dev 18: 116-122.

MOSAMMAPARASTN, SHIY. (2010) Reversal of histone methylation: biochemical and molecular mechanisms of histone demethylases. Annu Rev Biochem 79: 155-179.

NAKAJIMA Y, KANEKO H, MURRAY G, BURKE RD. (2004) Divergent patterns of neural development in larval echinoids and asteroids. Evol Dev 6: 95-104.

RAGUSA, M.A., LONGO, V., EMANUELE, M., COSTA,S., GIANGUZZA,F. (in press) In silico characterization of the neural alpha tubulin gene promoter of the sea urchin embryo Paracentrotus lividus by phylogenetic footprinting. Mol Biol Rep DOI: 10.1007/s11033-011-1016-7

RANDO OJ, AHMAD K. (2007) Rules and regulation in the primary structure of chromatin. Curr Opin Cell Biol 19: 250-256.

ROBERTSON AG, BILENKY M, TAM A, ZHAO Y, ZENG T, THIESSEN N, CEZARD T, FEJES AP, WEDERELL ED, CULLUM R, EUSKIRCHEN G, KRZYWINSKI M, BIROLI, SNYDERM, HOODLESS PA, HIRST M, MARRAMA, JONES SJM. (2008) Genome-wide relationship between histone $\mathrm{H} 3$ lysine 4 mono- and tri-methylation and transcription factor binding. Genome Res 18: 1906-1917.

RUDOLPH T, YONEZAWA M, LEIN S, HEIDRICH K, KUBICEK S, SCHÄFER C PHALKE S, WALTHER M, SCHMIDT A, JENUWEIN T, REUTER G. (2007) Heterochromatin formation in Drosophila is initiated through active removal of H3K4 methylation by the LSD1 homolog SU(VAR)3-3. Mol Cell 26: 103-115.

SIPPELAE, SAUERESSIG H, HUBER MC, HOEFER HC, STIEFA, BORGMEYERU, BONIFER C. (1996) Identification of cis-acting elements as DNase I hypersensitive sites in lysozyme gene chromatin. Meth Enzymol 274: 233-246.

TUSZYNSKI JA, CARPENTER EJ, HUZIL JT, MALINSKI W, LUCHKO T, LUDUENA RF. (2006) The evolution of the structure of tubulin and its potential consequences for the role and function of microtubules in cells and embryos. Int J Dev Biol 50: 341-358.

VAQUERO A. (2009) The conserved role of sirtuins in chromatin regulation. Int $J$ Dev Biol 53: 303-322.

VAN INGEN H, VAN SCHAIK FMA, WIENK H, BALLERING J, REHMANN H, DECHESNE AC, KRUIJZER JAW, LISKAMP RMJ, TIMMERS HTM, BOELENS R. (2008) Structural insight into the recognition of the H3K4me3 mark by the TFIID subunit TAF3. Structure 16: 1245-1256.

VON HOLT C, BRANDT WF, GREYLING HJ, LINDSEY GG, RETIEF JD, RODRIGUES JD, SCHWAGER S, SEWELL BT. (1989) Isolation and characterization of histones. Meth Enzymol 170: 431-523.

YAGUCHI S, YAGUCHI J, BURKE RD. (2006) Specification of ectoderm restricts the size of the animal plate and patterns neurogenesis in sea urchin embryos. Development 133: 2337-2346. 


\section{Further Related Reading, published previously in the Int. J. Dev. Biol.}

The conserved role of sirtuins in chromatin regulation

Alejandro Vaquero

Int. J. Dev. Biol. (2009) 53: 303-322

The evolution of the structure of tubulin and its potential consequences for the role and function of microtubules in cells and embryos

Jack A. Tuszynski, Eric J. Carpenter, J. Torin Huzil, Wojtek Malinski, Tyler Luchko and Richard F. Luduena

Int. J. Dev. Biol. (2006) 50: 341-358

Homeobox genes and sea urchin development

M Di Bernardo, D Bellomonte, S Castagnetti, R Melfi, P Oliveri and G Spinelli

Int. J. Dev. Biol. (2000) 44: 637-643

Spatial expression of alpha and beta tubulin genes in the late embryogenesis of the sea urchin Paracentrotus lividus

C Casano, M Ragusa, M Cutrera, S Costa and F Gianguzza

Int. J. Dev. Biol. (1996) 40: 1033-1041

Alpha-tubulin marker gene of neural territory of sea urchin embryos detected by whole-mount in situ hybridization

F Gianguzza, C Casano and M Ragusa

Int. J. Dev. Biol. (1995) 39: 477-483

ISI Impact Factor $(2010)=2.86$
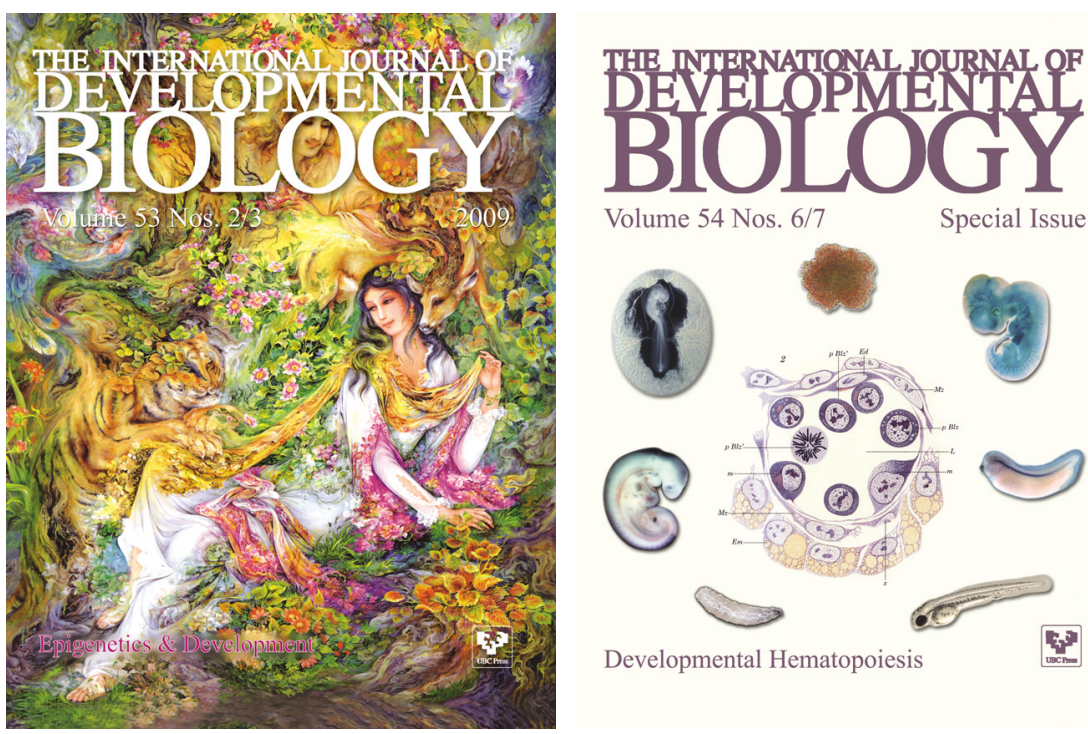

Volume 54 Nos. 6/7

Special Issue
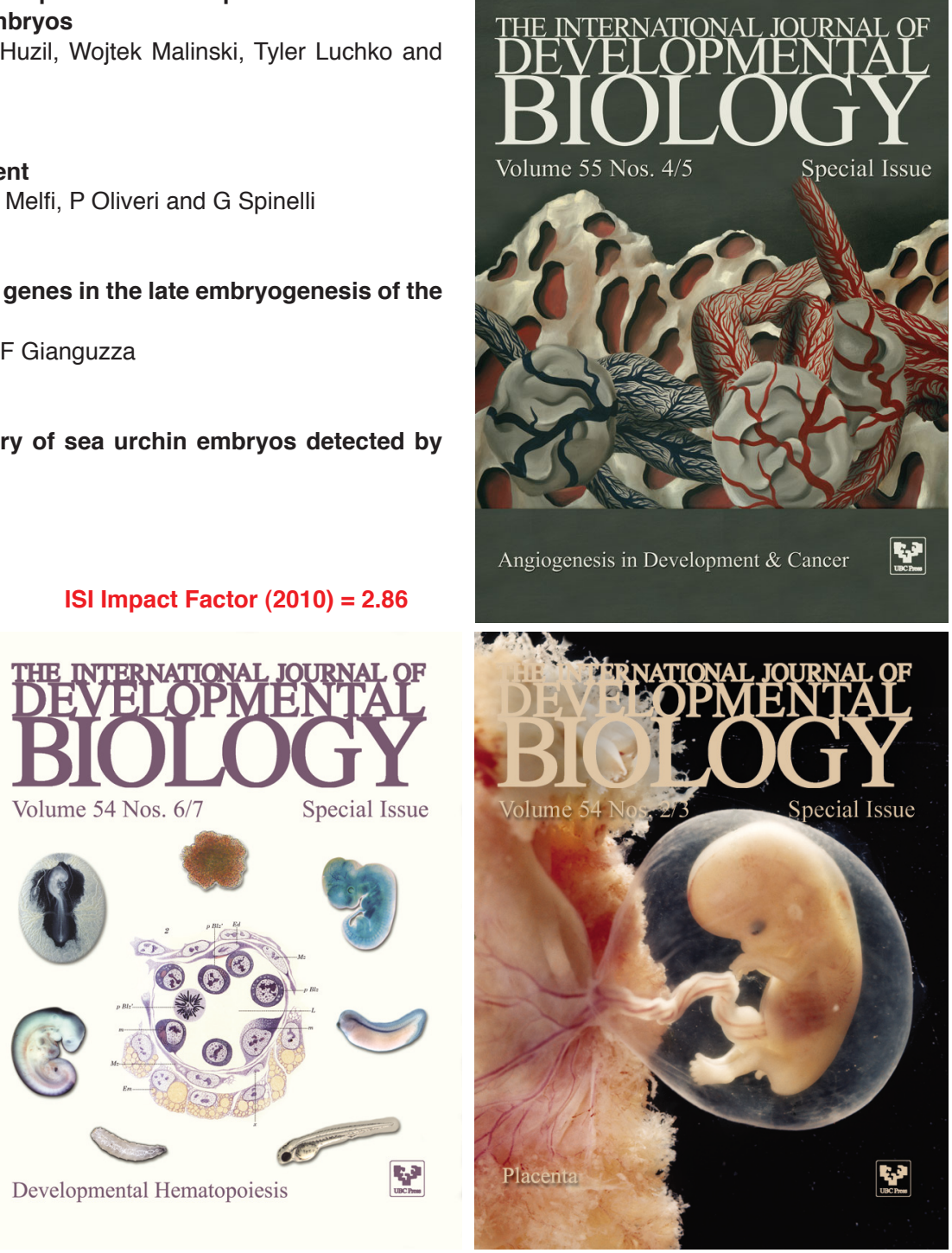

Developmental Hematopoiesis

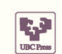

